$4^{\text {th }}$ International Meeting on Calcitonin Gene-Related Peptide (CGRP)

TheScientificWorld (2001) 1(S1), 27

ISSN 1532-2246; DOI 10.1100/tsw.2001.419

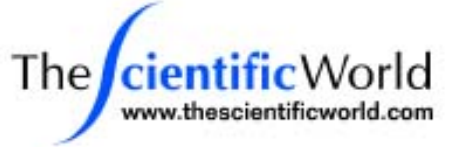

\title{
GENE TRANSFER OF CGRP PREVENTS CEREBRAL VASOCONSTRICTION AFTER SUBARACHNOID HEMORRHAGE
}

\author{
Donald D. Heistad, Andrew F. Russo, Frank M. Faraci, and Christopher G. Sobey \\ University of Iowa College of Medicine and VA Medical Center
}

Cerebral vasospasm occurs commonly after subarachnoid hemorrhage (SAH), and is the leading cause of morbidity and mortality after SAH. The mechanism of spasm after SAH is unclear, and prevention is ineffective. Our goal is to develop gene therapy to prevent cerebral vasospasm after SAH.

First, we developed a method to deliver genes to intracranial blood vessels. Instead of injecting a vector intravascularly, a recombinant adenoviral vector was injected into CSF through the cisterna magna. Excellent expression was observed around cerebral vessels at the base of the brain. We identified promoter-enhancers which provide expression throughout the duration of risk of vasospasm.

To identify an appropriate gene to transfer, we applied exogenous substances in vivo to the basilar artery of rats after SAH. Cerebral vasodilator responses to acetylcholine are impaired after $\mathrm{SAH}$, responses to activation of $\mathrm{K}_{\mathrm{ATP}}$ by aprikalim are augmented after $\mathrm{SAH}$, and responses to CGRP (which act in part by activation of $\mathrm{K}_{\mathrm{ATP}}$ ) are augmented after $\mathrm{SAH}$.

We therefore cloned the preproCGRP gene and constructed a recombinant adenovirus (AdCGRP). In rabbits after SAH, CGRP levels (by RIA) were 400-fold greater (2.0 $\pm 0.3 \mathrm{nmol} / \mathrm{l})$ after AdCGRP than after a control virus.

Constrictor responses to serotonin of the basilar artery ex vivo are exaggerated after SAH, and these constrictor responses were inhibited by AdCGRP in vivo. We examined constrictor responses to SAH of the basilar artery in rabbits in vivo with angiography; intracisternal injection of AdCGRP after SAH completely prevented cerebral vasoconstriction.

Before this method can be used after SAH in humans, a better vector (which produces little inflammation) will be needed, or we will need to inject a lower dose of virus to reduce the inflammatory response. We have developed two methods to increase efficiency of gene transfer to intracranial vessels, to allow use of a lower dose of virus.

In summary, gene transfer of CGRP to intracranial blood vessels is a promising approach to prevent cerebral vasospasm and stroke after SAH. 

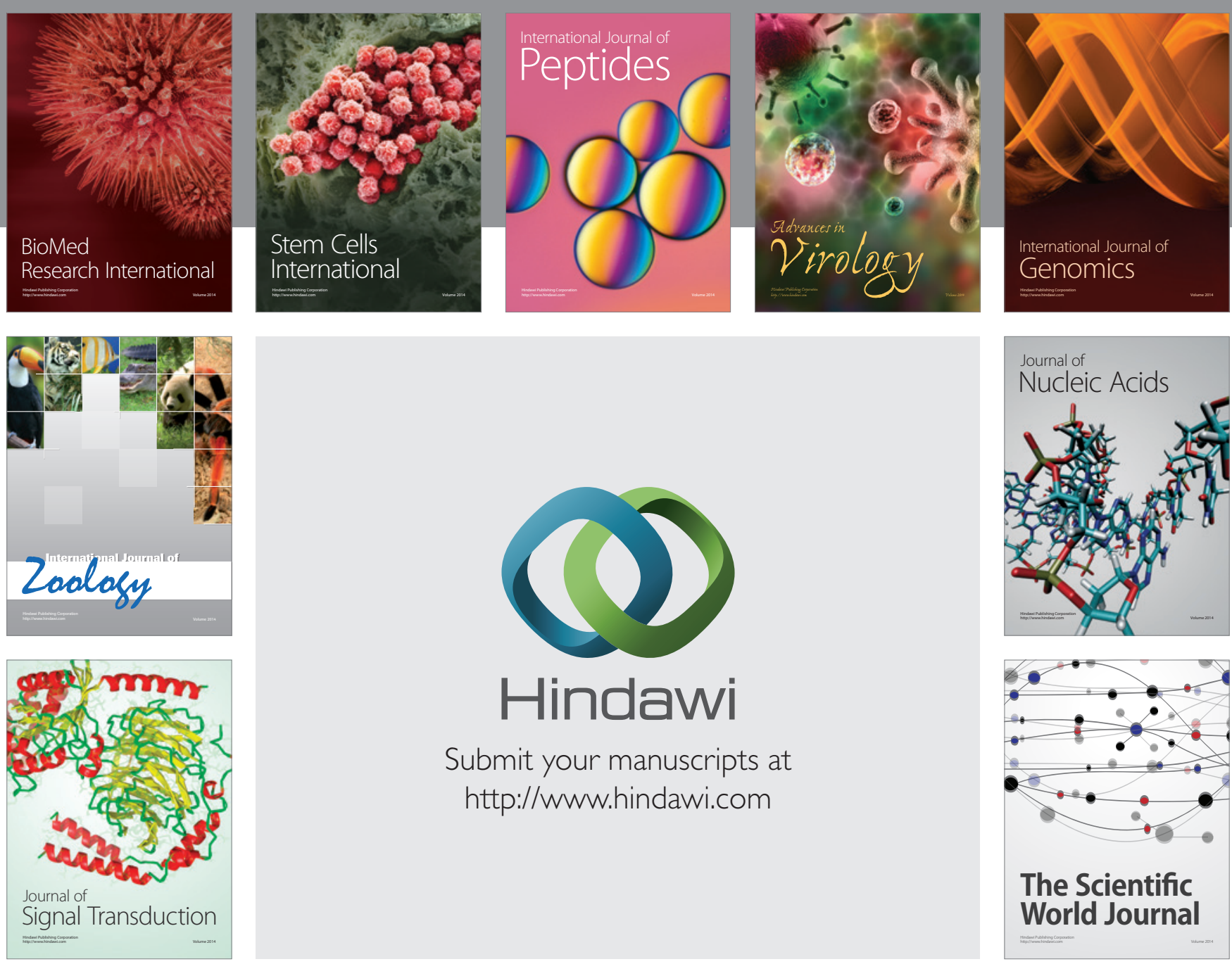

Submit your manuscripts at

http://www.hindawi.com
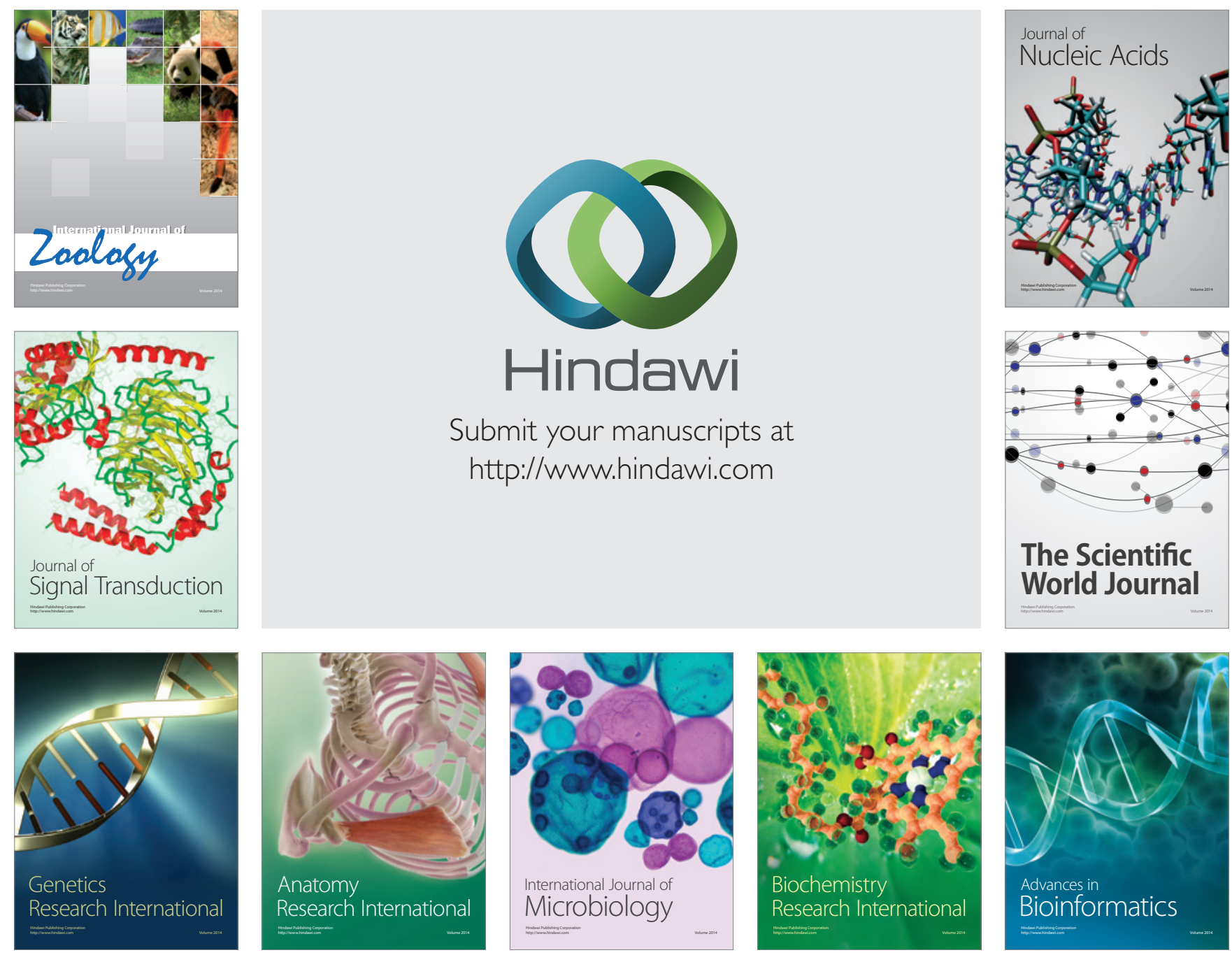

The Scientific World Journal
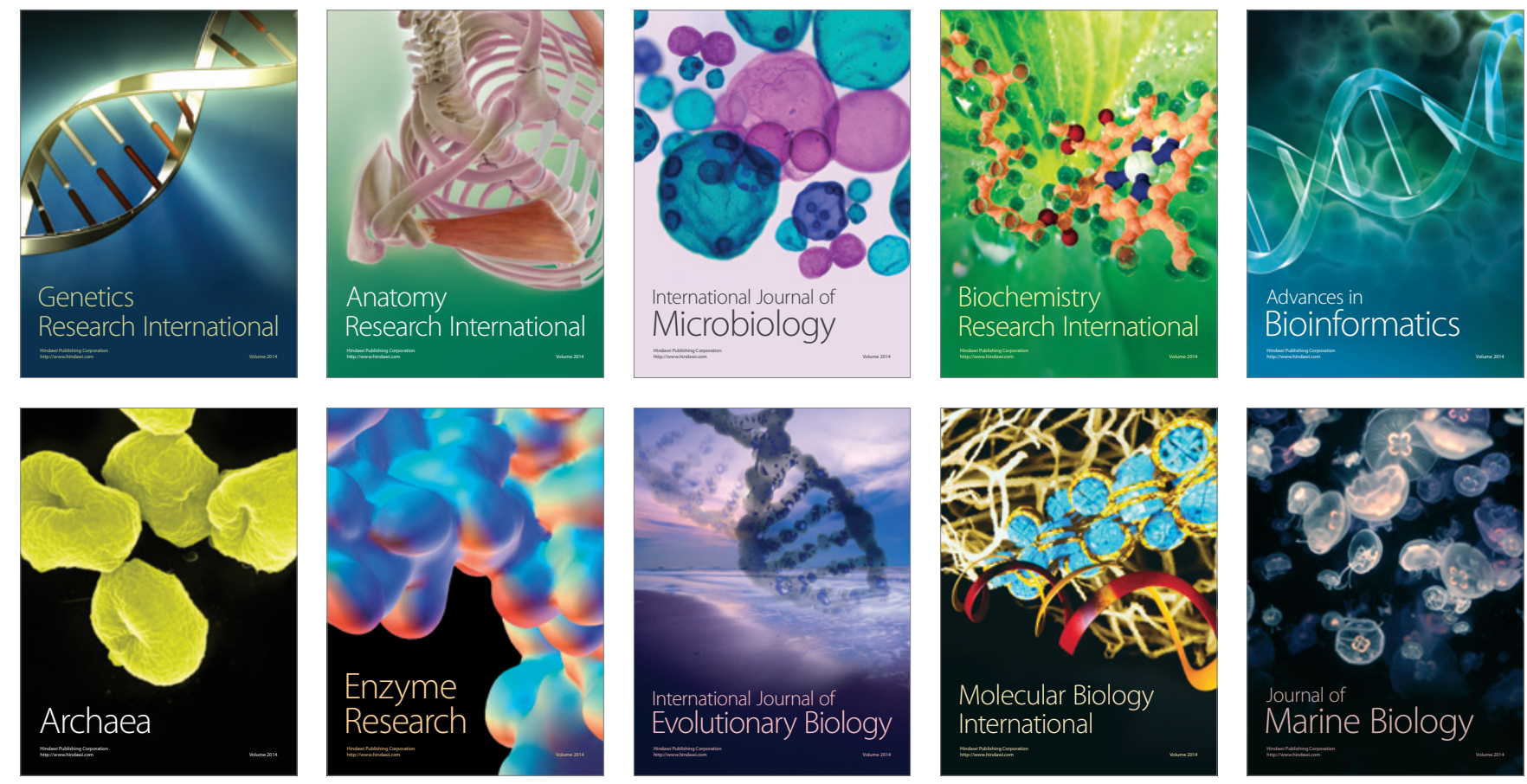